\title{
New Therapeutic Targets in the Neurovascular Pathway in Alzheimer's Disease
}

\author{
Berislav V. Zlokovic \\ Center for Neurodegenerative and Vascular Brain Disorders and Frank P. Smith Laboratory for Neuroscience and \\ Neurosurgical Research, Departments of Neurosurgery and Neurology, University of Rochester Medical School, Rochester, \\ New York 14642
}

\begin{abstract}
Summary: Recent findings indicate that neurovascular dysfunction is an integral part of Alzheimer's disease (AD). Changes in the vascular system of the brain may significantly contribute to the onset and progression of dementia and to the development of a chronic neurodegenerative process. In contrast to the neurocentric view, which proposes that changes in chronic neurodegenerative disorders, including $\mathrm{AD}$, can be attributed solely to neuronal disorder and neuronal dysfunction, the neurovascular concept proposes that dysfunction of non-neuronal neighboring cells and disintegration of neurovascular unit function may contribute to the pathogenesis of dementias in the elderly population, and understanding these processes will be crucial for the development of new therapeutic approaches to normalize both vascular and neuronal dysfunction. In this review, I discuss
\end{abstract}

briefly the role of vascular factors and vascular disorder in $\mathrm{AD}$, the link between cerebrovascular disorder and $\mathrm{AD}$, the clearance hypothesis for AD, the role of RAGE (receptor for advanced glycation end products) and LRP (low density lipoprotein receptor related protein 1) in maintaining the levels of amyloid $\beta$-peptide $(\mathrm{A} \beta)$ in the brain by controlling its transport across the blood-brain barrier (BBB), and the role of impaired vascular remodeling and cerebral blood flow dysregulation in the disease process. The therapeutic strategies based on new targets in the AD neurovascular pathway, such as RAGE and LRP receptors, and on a few selected genes implicated in $\mathrm{AD}$ neurovascular dysfunction (e.g., mesenchyme homeobox gene 2 and myocardin) are also discussed. Key Words: Blood-brain barrier, RAGE, LRP, amyloid $\beta$-peptide, ischemia, angiogenesis, dementia.

\section{INTRODUCTION}

Several epidemiologic studies, including the large population-based Rotterdam study, ${ }^{1,2}$ have suggested that vascular risk factors might be responsible for cognitive decline in the elderly population. Old age, atherosclerosis, stroke, hypertension, transient ischemic attacks, cardiac disease, the $\epsilon 4$ allele of the apolipoprotein E gene, elevated homocysteine levels, hyperlipidemia, metabolic syndrome, obesity, and diabetes are among the risk factors for both vascular dementia and Alzheimer's disease (AD).$^{3-6}$ It remains unclear whether controlling vascular risk factors, vascular brain disorder, and metabolic syndrome in early-diagnosed $\mathrm{AD}$ individuals will prevent progressive cognitive decline and dementia.

Progressive cognitive decline in $\mathrm{AD}$ is associated with

Address correspondence and reprint requests to: Berislav V. Zlokovic, M.D., Ph.D., Arthur Kornberg Medical Research Building, 601 Elmwood Avenue, Box 645, Rochester, NY 14642. E-mail: Berislav_Zlokovic@urmc.rochester.edu. neurovascular dysfunction, ${ }^{3,4}$ chronic neurodegenerative process, accumulation of neurotoxic amyloid $\beta$-peptide $(\mathrm{A} \beta)$ on blood vessels and in brain parenchyma, ${ }^{7-9}$ intraneuronal lesions and neurofibrillary tangles (NFT),${ }^{10-12}$ and vascular deposition of amyloid resulting in cerebral amyloid angiopathy (CAA). ${ }^{13,14}$ Whether neurovascular dysfunction and vascular lesions precede a chronic neurodegenerative process, as suggested by a number of recent studies reviewed elsewhere, ${ }^{15}$ or if they develop in response to neurodegeneration is controversial and has been a subject of many debates. However, not knowing the exact relationship between vascular and neuronal lesions in $\mathrm{AD}$ makes it more difficult to develop new therapeutic approaches for treating cognitive decline, especially in AD cases with prominent cerebrovascular and metabolic comorbidity.

\section{ROLE OF BRAIN ISCHEMIA}

Large cerebral arteries in AD do not develop CAA, but are frequently affected by atherosclerosis. ${ }^{16,17}$ The Nun 


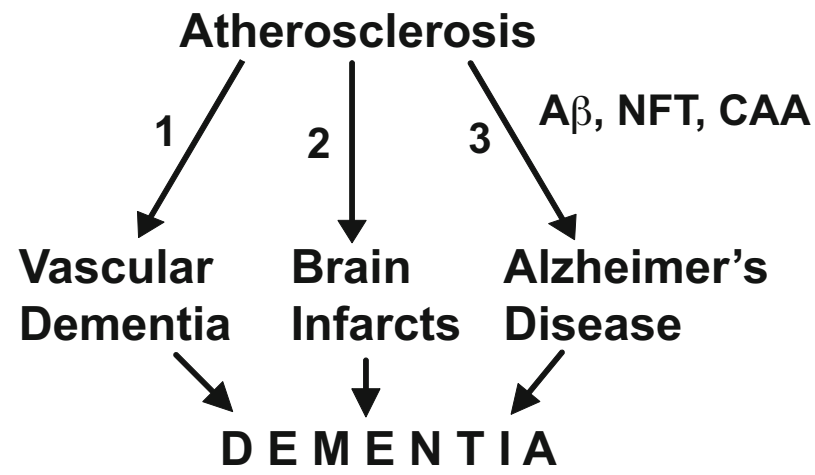

FIG. 1. Schematic illustrating different pathways by which atherosclerosis may lead to cognitive decline in the elderly. Pathway 1 leads directly to vascular dementia. Pathway 2 leads to brain infarcts increasing the risk for dementia. Pathway 3 leads to Alzheimer's disease pathology with accumulation of amyloid $\beta$-peptide $(A \beta)$ and development of neurofibrillary tangles (NFT) and cerebral amyloid angiopathy (CAA). Molecular mechanisms in the cerebral vasculature and at the blood-brain barrier underlying pathways 1, 2, and 3 are largely unknown.

Study ${ }^{18}$ found that cerebrovascular disease determines the presence and severity of $\mathrm{AD}$, and that demented $\mathrm{AD}$ individuals with one or two lacunar infarcts have a much steeper drop in cognitive function than do individuals with no brain infarcts, irrespective of the number of NFT in neocortex. The Rotterdam Scan Study, ${ }^{19}$ a prospective, population-based study with 1015 patients, demonstrated that silent brain infarcts detected on magnetic resonance imaging (MRI) doubled the risk for dementia in elderly people, with a hazard factor of 2.26. The Rotterdam Study, with 1730, subjects found that cerebral hypoperfusion preceded the onset of clinical dementia and that reductions in cerebral blood flow $(\mathrm{CBF})$ velocity occurred before cognitive decline and before hippocampal and amygdalar atrophy were documented on MRI. ${ }^{2}$ Nonetheless, the exact pathway or pathways by which atherosclerosis and arteriolosclerosis contribute to cognitive decline, and the relationship between vascular brain damage, white matter hyperintensities on MRI, and cognitive decline, are still not completely understood. ${ }^{20}$ Figure 1 illustrates possible pathways by which atherosclerosis may lead to dementia. Whether progression of vascular disorder and dementia in $\mathrm{AD}$ could be controlled by a new class of agents exerting combined anticoagulant, anti-inflammatory and neuroprotective activities in the ischemic brain, such as activated protein $\mathrm{C}$ (APC), ${ }^{21}$ remains to be explored.

In rodents, ischemia increases $\mathrm{A} \beta$ production, ${ }^{3}$ accumulation of hyperphosphorylated tau in cortical neurons, and filament formation similar to that present in human neurodegenerative tauopathies and in $\mathrm{AD},{ }^{22,23}$ which suggests that hypoperfusion may generate neuropathological changes similar to those seen in AD individuals. Amyloid $\beta$-peptide is a potent vasoconstrictor in brain. ${ }^{24}$ In mice expressing $A \beta$-precursor protein (App), reduc- tions in endothelium-dependent regulation of cortical microcirculation $^{25}$ and $\mathrm{CBF}$ dysregulation in response to brain activation have been reported prior to neuropathological changes. ${ }^{26,27}$ Similarly, neurovascular uncoupling, reductions in $\mathrm{CBF}$, and low brain uptake of glucose have been shown in sporadic $\mathrm{AD}$ prior to cognitive decline. ${ }^{28-30}$

\section{CLEARANCE HYPOTHESIS FOR AD}

Most AD cases ( $\sim 99 \%)$ present with late onset (i.e., $>65$ years of age) and without clear evidence of genetic transmission. ${ }^{31}$ Late-onset AD individuals do not normally have increased production of $\mathrm{A} \beta$. Instead, $\mathrm{A} \beta$ likely accumulates in the brain of $\mathrm{AD}$ individuals because of deficient clearance from brain, ${ }^{32-35}$ as illustrated in Figure 2. Recent evidence suggests that plaques are generated on blood vessels due to faulty $\mathrm{A} \beta$ clearance across the blood-brain barrier (BBB) or during its transport by passive diffusion across Virchow-Robin perivascular arterial spaces. ${ }^{15}$

Amyloid $\beta$-peptide is central to the development of brain pathology in AD. ${ }^{7-9,12,33,36,37}$ Patients with sporadic $\mathrm{AD}$ and familial $\mathrm{AD}(\mathrm{FAD} ;<1 \%$ of all $\mathrm{AD}$ cases) typically develop focal increases in brain $A \beta$ levels midway through the disease process or at a later stage. Elevated $\mathrm{A} \beta$ levels in brain generate neurotoxic $\mathrm{A} \beta$ oligomer species, which may disrupt normal brain function $^{37}$ or lead to $\mathrm{A} \beta$ deposits in the form of senile plaques. In murine models of AD, such as APP-overexpressing mice with Swedish mutation $\left(A P P s w^{+/-}\right)$and transgenic $A P P$ mice harboring vasculotropic Dutch, Iowa, and Swedish triple APP mutations, dense plaques initially develop on blood vessels or as classical CAA. ${ }^{38-40}$

In more than $80 \%$ of $\mathrm{AD}$ cases, the pial and intracerebral arteries are affected by CAA. ${ }^{14}$ Pathogenic levels of vasculotropic mutant forms of $\mathrm{A} \beta$ (e.g., Dutch, Iowa, Arctic, Flemish, Italian) accelerate degeneration of the vessel wall, thus contributing to hemorrhagic strokes, as in familial forms of AD. ${ }^{13}$

How we might prevent $\mathrm{A} \beta$ accumulation by accelerating its clearance from brain is an emerging area of research, one that holds promise for the development of new future therapies for AD.

\section{RAGE AND LRP REGULATE A $\beta$ BLOOD-BRAIN BARRIER TRANSPORT}

\section{RAGE}

The receptor for advanced glycation end products (RAGE) is normally expressed at low levels in brain, except for the endothelium of brain capillaries and small arterioles (A. Sagare, R. Deane, R.D. Bell, and B.V. Zlokovic, unpublished observations). However, under pathophysiologi- 


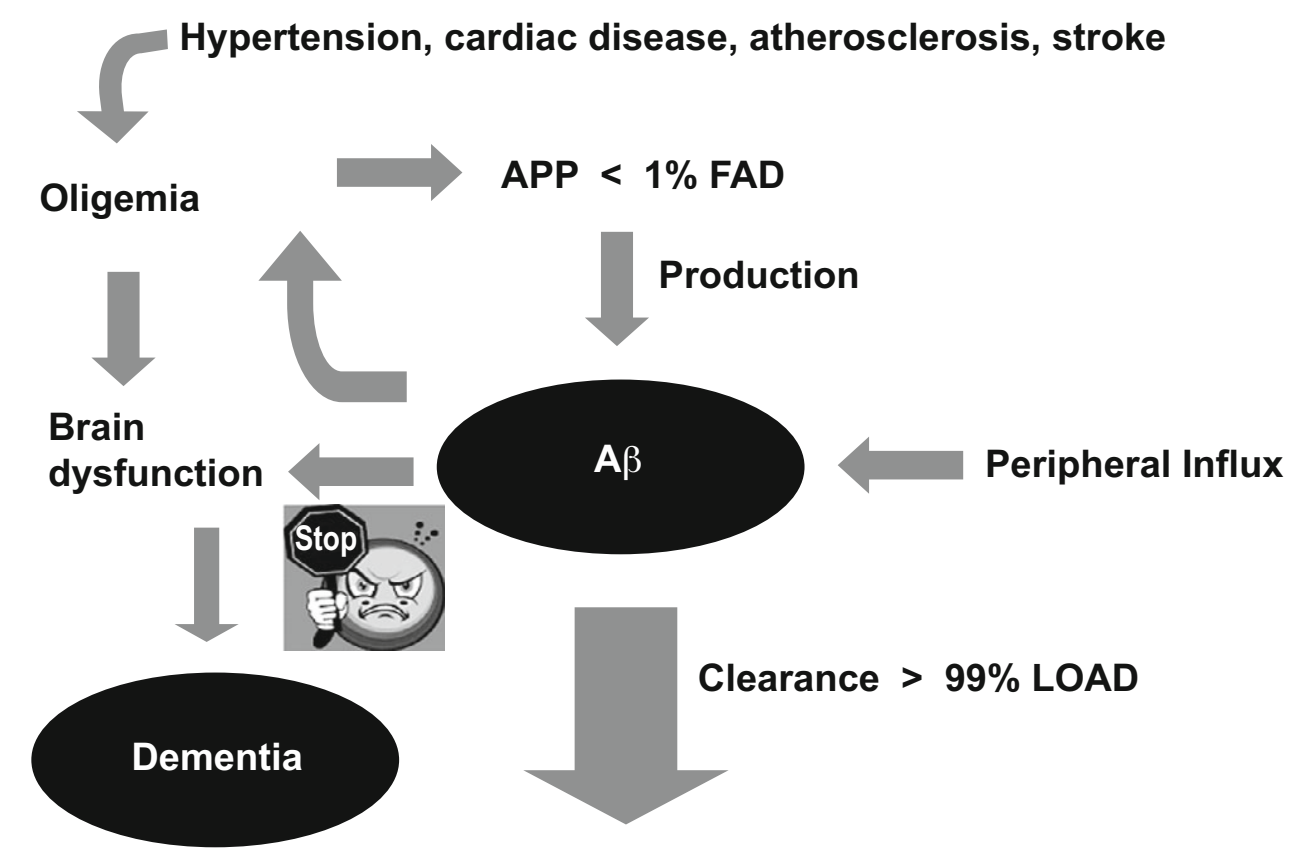

FIG. 2. The clearance hypothesis for Alzheimer's disease (AD). Amyloid $\beta$-peptide accumulates in late-onset $A D(L O A D)(\sim 99 \%$ of all $A D$ cases), likely because of an imbalance in its production from the precursor APP protein, peripheral re-entry (influx) from blood, and clearance from brain. When the clearance mechanisms fail, $A \beta$ accumulates, which affects brain function and reduces blood flow, resulting in oligemia. Oligemia increases $A \beta$ production, which amplifies the positive feedback loop for $A \beta$ accumulation. Vascular risk factors such as stroke, hypertension, cardiac disease, or atherosclerosis may all aggravate brain oligemia, which alters the balance between $A \beta$ production and clearance in favor of production. In familial $A D$ (FAD; $<1 \%$ of all $A D$ cases), an increased $A \beta$ production outweighs the clearance capacity and $A \beta$ accumulates in the brain, initiating the pathogenic cascade similar that found in LOAD.

cal conditions such as those associated with the accumulation of RAGE ligands on blood vessels (e.g., deposition of proteins modified by glycation and oxidation, whether AGE proteins or $A \beta$ ), the expression of cerebrovascular RAGE is increased. In $\mathrm{AD}$ and $\mathrm{AD}$ models, RAGE expression increases by several-fold in affected cerebral vessels and in microglia and neurons. ${ }^{41-46}$

RAGE binds different forms of $A \beta$, and its reaction with $\mathrm{A} \beta$ at the luminal membrane of the BBB (FIG. 3) mediates 1 ) re-entry of circulating $A \beta$ into the brain across the $\mathrm{BBB}$, followed by $\mathrm{A} \beta$ binding to neurons; 2) NF- $\kappa B$-dependent activation of endothelium with expression of proinflammatory cytokines and adhesion molecules; and 3) secretion of endothelin-1 resulting in $\mathrm{CBF}$ reductions. In addition to the observations in mice and rats, transport of $\mathrm{A} \beta$ peptides from blood to brain across the BBB has been shown in other species, including guinea pigs and nonhuman primates. ${ }^{47,48}$ Compared with other small peptides, such as vasopressin or enkephalins, ${ }^{49,50}$ transport of $A \beta 40$ across the mouse BBB was two- to threefold faster, although it was only a fraction of the rate determined for amino acid transport either across the BBB or the choroid plexus. ${ }^{51,52}$

RAGE is an important therapeutic target in AD. RAGE-A $\beta$ interaction on neurons can kill neurons directly by producing oxidative damage or indirectly by activating microglia. ${ }^{41}$ Inhibition of RAGE-A $\beta$ interac- tion in the affected blood vessels blocks $A \beta$ influx across the $\mathrm{BBB}$ and the associated oxidant stress and neuroinflammation. ${ }^{43}$ RAGE and $\mathrm{A} \beta$ blockers are currently being tested in $\mathrm{AD}$ patients for safety and efficacy. A double-blind, placebo-controlled, randomized, multicenter study conducted under the Alzheimer's Disease Cooperative Study to evaluate the efficacy and safety of 18 months of treatment with PF-04494700 (TTP488) in participants with mild-to-moderate Alzheimer's disease began patient enrollment in December 2007.

\section{LRP}

Low density lipoprotein receptor related protein 1 (LRP), a member of the LDL receptor family, is a major clearance receptor for $\mathrm{A} \beta$ at the BBB. ${ }^{53} \mathrm{~A} \beta$ binding to LRP is the first step in $A \beta$ clearance from brain mediated by transvascular $\mathrm{A} \beta$ transport across the $\mathrm{BBB}^{39,53-55}$ (FIG. 3). Substitution at codon 22 of LRP, as in Dutch type FAD, reduces clearance of $A \beta$ from the CSF and brain into blood. ${ }^{56}$ Reduced expression of LRP was found during normal aging in rodents, nonhuman primates, and in $\mathrm{AD}$ individuals associated with positive staining of cerebral vessels for $\mathrm{A} \beta 40$ and $\mathrm{A} \beta 42 .{ }^{39,45,53}$ Mice with severely depleted LRP levels at the BBB develop $\mathrm{A} \beta$ accumulations when crossed with APPoverexpressing mice. ${ }^{57}$ Binding of $A \beta$ to apolipoprotein $\mathrm{J}$ and $\mathrm{E}$ and $\alpha 2$-macroglobulin critically alters $\mathrm{A} \beta$ clearance rates from the brain and can influence vascular and 


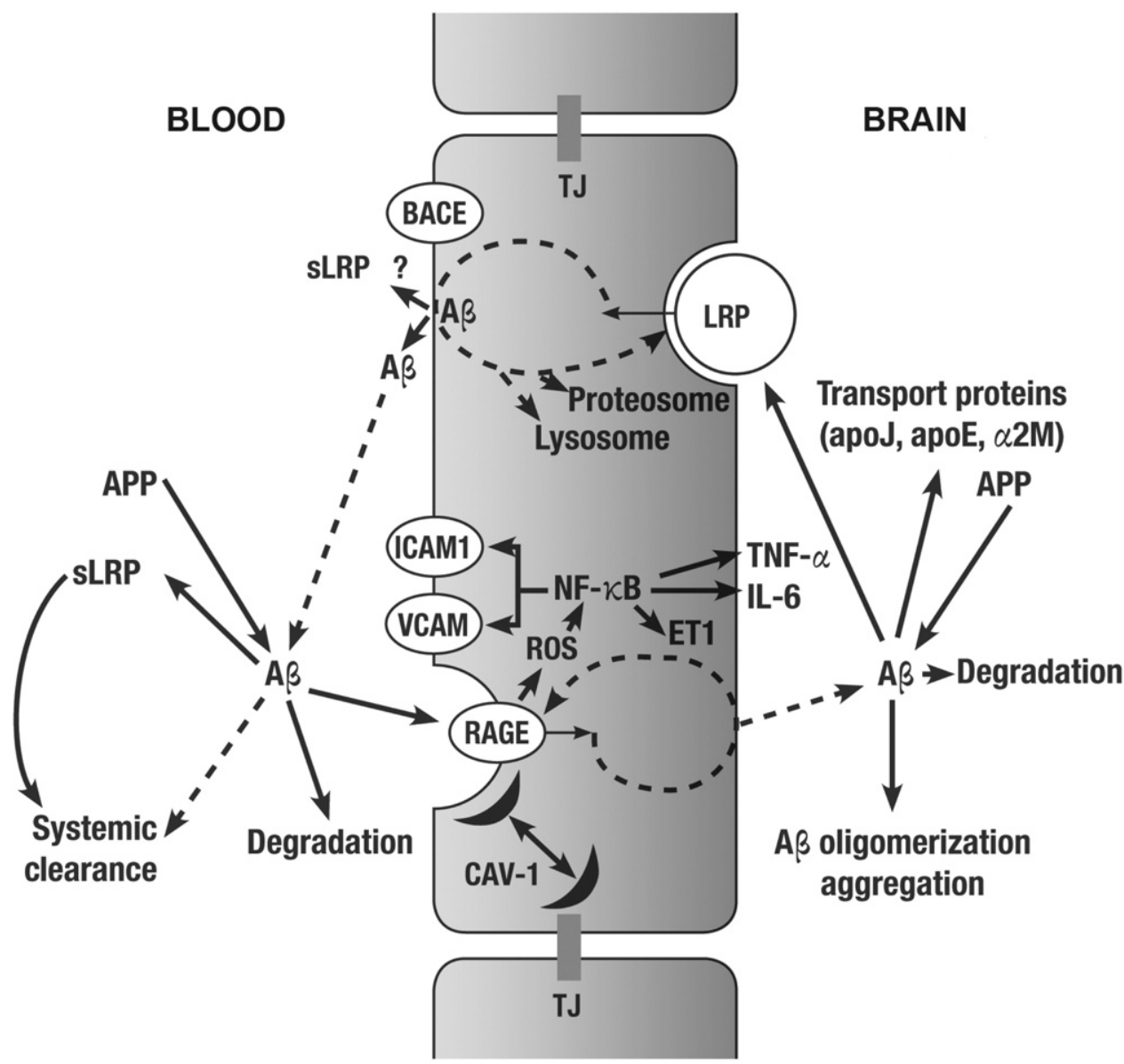

FIG. 3. Transport equilibrium for amyloid $\beta$-peptide $(A \beta)$ at the blood-brain barrier (BBB). The cell surface LRP on the abluminal membrane binds different forms of $A \beta$ (e.g., monomers, oligomers, aggregates) and initiates $A \beta$ transcytosis across the BBB followed by its export into the circulation. In the case of A $\beta$ overload, LRP (low density lipoprotein receptor related protein 1 ) loses its normal protein conformation and undergoes the accelerated proteosomal degradation. $A \beta$ efflux is influenced by its transport binding proteins in the brain, such as apolipoproteins $\mathrm{E}$ and $\mathrm{J}$ (apoE, ApoJ), or $\alpha 2$-macroglobulin $(\alpha 2 \mathrm{M})$. $\beta$-Secretase (BACE) cleaves the $\mathrm{N}$-terminus extracellular domain of LRP1, which generates a soluble form of LRP (sLRP). In human plasma, more than $70 \%$ of $A \beta$ is normally bound to sLRP. Native plasma sLRP is a major endogenous peripheral sink agent for $A \beta$. The remaining $A \beta$ in the plasma is bound to other $A \beta$-transporting proteins (e.g., apoJ). A small fraction of plasma $A \beta$ is free. On the luminal membrane, free $A \beta$ that escapes the sLRP surveillance in the blood interacts with the receptor for advanced glycation end products (RAGE). A $\beta-R A G E$ interaction mediates re-entry of $A \beta$ from blood to brain (influx), and activates the endothelium through reactive oxygen species (ROS)-induced nuclear translocation of NF-кB. This triggers secretion of proinflammatory cytokines, such as interleukin-6 (IL-6), tumor-necrosis factor- $\alpha$ (TNF- $\alpha$ ), the expression of adhesion molecules at the BBB, such as intercellular adhesion molecule 1 (ICAM1) and vascular cell adhesion molecule (VCAM), and secretion of endothelin-1, a suppressor of blood flow. Modified from reference 15 (Zlokovic BV. The blood-brain barrier in health and chronic neurodegenerative disorders. Neuron 2008;57:178-201.), with permission.

parenchymal accumulation of $A \beta .^{35,55}$ Finally, LRP mediates $\mathrm{A} \beta$ systemic clearance from the liver. ${ }^{58}$

$\beta$-Secretase cleaves the N-terminal extracellular domain of LRP $^{59}$ and releases soluble LRP (sLRP) in plasma. Normally, sLRP binds $70 \%$ to $90 \%$ of $\mathrm{A} \beta$ in human plasma. ${ }^{60} \mathrm{~A} \beta$ binding to sLRP is significantly reduced in late-stage cases of late-onset AD; this, in turn, may elevate brain $\mathrm{A} \beta$, because of reductions in the endogenous peripheral sink activity of sLRP. Recombinant LRP clusters can effectively sequester $\mathrm{A} \beta$ in AD plasma and in $A P P s w^{+/-}$mice, promoting $\mathrm{A} \beta$ efflux from the mouse brain. ${ }^{60}$ Thus, LRP fragments may have therapeutic potential as novel $\mathrm{A} \beta$ clearance agents or in sLRP replacement therapy for $\mathrm{AD}$.
$M d r l a / M d r l b$ null mice lack P-gp at the $\mathrm{BBB}$ and express lower levels of LRP in brain capillaries. ${ }^{54}$ $M d r l a / M d r l b$ null mice exhibit reduced clearance of $\mathrm{A} \beta$ from brain, whereas APP mice lacking P-gp have accelerated accumulation of $\mathrm{A} \beta$ and amyloid deposition. Thus, the Mdrla and Mdrlb genes may influence $\mathrm{A} \beta$ clearance either directly through P-gp, indirectly through LRP, or through both.

\section{IMPAIRED VASCULAR REMODELING}

Reduced microvascular density, fragmented and atrophic string vessels, irregularity of capillary endothelial surfaces, reductions in the vessel diameter, thickening of 
capillary basement membranes, and collagen accumulation in basement membranes have been described in AD. ${ }^{61,62}$ It has been suggested that the degeneration of brain capillary endothelium seen in AD and AD models may reflect aberrant sprouting angiogenesis in response to chronic brain hypoxia. ${ }^{15} \mathrm{~A}$ recent report found extremely low levels of expression of the mesenchyme homeobox gene 2 (MEOX2) in the BBB of AD individuals. ${ }^{63}$ MEOX2 normally regulates vascular cell differentiation and repair, and its expression in the adult brain is restricted to the vascular system. Low levels of MEOX2 in AD endothelium mediate abnormal responses to angiogenic factors such as vascular endothelial growth factor, resulting in premature vessel regression, reduced resting $\mathrm{CBF}$ and improper formation of the BBB ${ }^{63}$ Low levels of MEOX2 also promote proteasomal degradation of LRP, which lowers the $A \beta$-clearing capability at the $\mathrm{BBB}$, thus leading to $\mathrm{A} \beta$ accumulation on the blood vessels. Accumulation of $\mathrm{A} \beta$ on the abluminal membrane of the blood vessels is antiangiogenic, which amplifies the reductions in microcirculation in $\mathrm{AD}$ models $^{64,65}$ and possibly in AD. Thus, aberrant angiogenesis has an amyloidogenic effect at the $\mathrm{BBB}^{66}$ And could represent an important novel target IN AD.

Recent studies have also shown that the expression of two transcription factors that control differentiation of vascular smooth muscle cells (VSMC), the serum response factor (SRF) and myocardin (MYOCD), is increased in $\mathrm{AD}$, resulting in a hypercontractile phenotype in small cerebral arteries associated with brain hypoperfusion and diminished CBF responses to brain activation. ${ }^{67}$ These events may also contribute to the hypoperfusion observed in AD brains. Thus, drugs that specifically disrupt SRF-MYOCD interaction in small brain vessels may hold potential to improve brain perfusion and CBF dysregulation in AD.

\section{CONCLUSIONS}

Recent clinical observations provide strong evidence for the link between cerebrovascular disease and $\mathrm{AD}$, cognitive decline, or both. Here, we have briefly reviewed changes in the expression of key vascular receptors and genes in brain capillaries and small cerebral arteries in $\mathrm{AD}$ and in $\mathrm{AD}$ models that may lead to focal vascular and brain accumulations of $\mathrm{A} \beta$, reductions in the resting CBF, attenuated CBF responses to brain activation, and focal neuroinflammatory response. The activation of the neurovascular pathogenic pathway may, in turn, compromise synaptic and neuronal functions, ultimately leading to neuronal damage with accumulation of intraneuronal tangles, neuronal loss, and dementia. The early molecular changes within the neurovascular pathway may offer new therapeutic targets for controlling progression of dementia in $\mathrm{AD}$, including therapies based on the receptors RAGE and LRP or on genes implicated in the neurovascular AD model, such as $M E O X 2$, or SRF and MYOCD.

Acknowledgments: The author thanks the National Institutes of Health (grants R37 AG023084 and R37 NS34467) and the Zilkha family for supporting his research. The author also wishes to thank Dr. Abhay Sagare for his help in preparing the figures, and Dr. Eleanor Carson-Walter for careful reading of the manuscript.

\section{REFERENCES}

1. Hofman A, Ott A, Breteler MM, et al. Atherosclerosis, apolipoprotein E, and prevalence of dementia and Alzheimer's disease in the Rotterdam Study. Lancet 1997;349:151-154.

2. Ruitenberg A, den Heijer T, Bakker SL, et al. Cerebral hypoperfusion and clinical onset of dementia: the Rotterdam Study. Ann Neurol 2005;57:789-794.

3. Iadecola C. Neurovascular regulation in the normal brain and in Alzheimer's disease. Nat Rev Neurosci 2004;5:347-360.

4. Zlokovic BV. Neurovascular mechanisms of Alzheimer's neurodegeneration. Trends Neurosci 2005;28:202-208.

5. de la Torre JC. How do heart disease and stroke become risk factors for Alzheimer's disease? Neurol Res 2006;28:637-644.

6. Luchsinger JA, Reitz C, Patel B, Tang MX, Manly JJ, Mayeux R. Relation of diabetes to mild cognitive impairment. Arch Neurol 2007;64:570-575.

7. Rovelet-Lecrux A, Hannequin D, Raux G, et al. APP locus duplication causes autosomal dominant early-onset Alzheimer disease with cerebral amyloid angiopathy. Nat Genet 2006;38:24-26.

8. Hardy J. A hundred years of Alzheimer's disease research. Neuron 2006;52:3-13.

9. Deane R, Zlokovic BV. Role of the blood-brain barrier in the pathogenesis of Alzheimer's disease. Curr Alzheimer Res 2007;4: 191-197.

10. Lee VM, Balin BJ, Otvos L Jr, Trojanowski JQ. A68: a major subunit of paired helical filaments and derivatized forms of normal Tau. Science 1991;251:675-678.

11. Santacruz K, Lewis J, Spires T, et al. Tau suppression in a neurodegenerative mouse model improves memory function. Science 2005;309:476-481.

12. Tanzi RE. The synaptic A $\beta$ hypothesis of Alzheimer disease. Nat Neurosci 2005;8:977-979.

13. Ghiso J, Frangione B. Amyloidosis and Alzheimer's disease. Adv Drug Deliv Rev 2002;54:1539-1551.

14. Greenberg SM, Gurol ME, Rosand J, Smith EE. Amyloid angiopathy-related vascular cognitive impairment. Stroke 2004;35:26162619.

15. Zlokovic BV. The blood-brain barrier in health and chronic neurodegenerative disorders. Neuron 2008;57:178-201.

16. Casserly I, Topol E. Convergence of atherosclerosis and Alzheimer's disease: inflammation, cholesterol, and misfolded proteins. Lancet 2004;363:1139-1146.

17. Beach TG, Wilson JR, Sue LI, et al. Circle of Willis atherosclerosis: association with Alzheimer's disease, neuritic plaques and neurofibrillary tangles. Acta Neuropathol 2007;113:13-21.

18. Snowdon DA, Greiner LH, Mortimer JA, Riley KP, Greiner PA, Markesbery WR. Brain infarction and the clinical expression of Alzheimer disease. The Nun Study. JAMA 1997;277:813-817.

19. Vermeer SE, Prins ND, den Heijer T, Hofman A, Koudstaal PJ, Breteler MM. Silent brain infarcts and the risk of dementia and cognitive decline. N Engl J Med 2003;348:1215-1222.

20. Chui HC, Zarow C, Mack WJ, et al. Cognitive impact of subcortical vascular and Alzheimer's disease pathology. Ann Neurol 2006;60:677-687.

21. Griffin JH, Zlokovic B, Fernandez JA. Activated protein C: potential therapy for severe sepsis, thrombosis, and stroke. Semin Hematol 2002;39:197-205.

22. Gordon-Krajcer W, Kozniewska E, Lazarewicz JW, Ksiezak-Reding H. Differential changes in phosphorylation of tau at PHF-1 and 
12E8 epitopes during brain ischemia and reperfusion in gerbils. Neurochem Res 2007;32:729-737.

23. Wen Y, Yang SH, Liu R, et al. Cdk5 is involved in NFT-like tauopathy induced by transient cerebral ischemia in female rats. Biochim Biophys Acta 2007;1772:473-483.

24. Thomas T, Thomas G, McLendon C, Sutton T, Mullan M. $\beta$-Amyloid-mediated vasoactivity and vascular endothelial damage. Nature 1996;380:168-171.

25. Iadecola C, Zhang F, Niwa K, et al. SOD1 rescues cerebral endothelial dysfunction in mice overexpressing amyloid precursor protein. Nat Neurosci 1999;2:157-161.

26. Niwa K, Younkin L, Ebeling C, et al. A $\beta$ 1-40-related reduction in functional hyperemia in mouse neocortex during somatosensory activation. Proc Natl Acad Sci U S A 2000;97:9735-9740.

27. Takano T, Han X, Deane R, Zlokovic B, Nedergaard M. Twophoton imaging of astrocytic $\mathrm{Ca}^{2+}$ signaling and the microvasculature in experimental mice models of Alzheimer's disease. Ann N Y Acad Sci 2007;1097:40-50.

28. Smith CD, Andersen AH, Kryscio RJ, et al. Altered brain activation in cognitively intact individuals at high risk for Alzheimer's disease. Neurology 1999;53:1391-1396.

29. Bookheimer SY, Strojwas MH, Cohen MS, et al. Patterns of brain activation in people at risk for Alzheimer's disease. N Engl J Med 2000;343:450-456.

30. Drake CT, Iadecola C. The role of neuronal signaling in controlling cerebral blood flow. Brain Lang 2007;102:141-152.

31. Tanzi RE, Bertram L. Twenty years of the Alzheimer's disease amyloid hypothesis: a genetic perspective. Cell 2005;120:545-555.

32. Zlokovic BV, Yamada S, Holtzman D, Ghiso J, Frangione B. Clearance of amyloid $\beta$-peptide from brain: transport or metabolism? Nat Med 2000;6:718-719.

33. Selkoe DJ. Clearing the brain's amyloid cobwebs. Neuron 2001; 32:177-180.

34. Tanzi RE, Moir RD, Wagner SL. Clearance of Alzheimer's A $\beta$ peptide: the many roads to perdition. Neuron 2004;43:605-608.

35. Holtzman DM, Zlokovic BV. Role of $\mathrm{A} \beta$ transport and clearance in the pathogenesis and treatment of Alzheimer's disease. In: Sisodia S, Tanzi RE, Alzheimer's disease: advances in genetics, molecular, and cellular biology. New York: Springer; 2007:179198.

36. Snyder EM, Nong Y, Almeida CG, et al. Regulation of NMDA receptor trafficking by amyloid- $\beta$. Nat Neurosci $2005 ; 8: 1051-1058$.

37. Haass C, Selkoe DJ. Soluble protein oligomers in neurodegeneration: lessons from the Alzheimer's amyloid $\beta$-peptide. Nat Rev Mol Cell Biol 2007;8:101-112.

38. Davis J, Xu F, Deane R, et al. Early-onset and robust cerebral microvascular accumulation of amyloid $\beta$-protein in transgenic mice expressing low levels of a vasculotropic Dutch/Iowa mutant form of amyloid $\beta$-protein precursor. J Biol Chem 2004;279: 20296-20306.

39. Deane R, Wu Z, Sagare A, et al. LRP/amyloid $\beta$-peptide interaction mediates differential brain efflux of $\mathrm{A} \beta$ isoforms. Neuron 2004;43:333-344.

40. Kumar-Singh S, Pirici D, McGowan E, et al. Dense-core plaques in Tg2576 and PSAPP mouse models of Alzheimer's disease are centered on vessel walls. Am J Pathol 2005;167:527-543.

41. Yan SD, Chen X, Fu J, et al. RAGE and amyloid- $\beta$ peptide neurotoxicity in Alzheimer's disease. Nature 1996;382:685-691.

42. Giri R, Shen Y, Stins M, et al. $\beta$-Amyloid-induced migration of monocytes across human brain endothelial cells involves RAGE and PECAM-1. Am J Physiol Cell Physiol 2000;279:C1772C1781.

43. Deane R, Du Yan S, Submamaryan RK, et al. RAGE mediates amyloid- $\beta$ peptide transport across the blood-brain barrier and accumulation in brain. Nat Med 2003;9:907-913.

44. LaRue B, Hogg E, Sagare A, et al. Method for measurement of the blood-brain barrier permeability in the perfused mouse brain: application to amyloid- $\beta$ peptide in wild type and Alzheimer's Tg2576 mice. J Neurosci Methods 2004;138:233-242.

45. Donahue JE, Flaherty SL, Johanson CE, et al. RAGE, LRP-1, and amyloid- $\beta$ protein in Alzheimer's disease. Acta Neuropathol 2006; $112: 405-415$
46. Herring A, Yasin H, Ambrée O, Sachser N, Paulus W, Keyvani K. Environmental enrichment counteracts Alzheimer's neurovascular dysfunction in TgCRND8 mice. Brain Pathol 2008;18:32-39.

47. Martel CL, Mackic JB, McComb JG, Ghiso J, Zlokovic BV. Blood-brain barrier uptake of the 40 and 42 amino acid sequences of circulating Alzheimer's amyloid $\beta$ in guinea pigs. Neurosci Lett 1996;206:157-160.

48. Mackic JB, Bading J, Ghiso J, et al. Circulating amyloid- $\beta$ peptide crosses the blood-brain barrier in aged monkeys and contributes to Alzheimer's disease lesions. Vascul Pharmacol 2002;38:303-313.

49. Zlokovic BV, Hyman S, McComb JG, Lipovac MN, Tang G, Davson H. Kinetics of arginine-vasopressin uptake at the bloodbrain barrier. Biochim Biophys Acta 1990;1025:191-198.

50. Zlokovic BV, Mackic JB, Djuricic B, Davson H. Kinetic analysis of leucine-enkephalin cellular uptake at the luminal side of the blood-brain barrier of an in situ perfused guinea-pig brain. J Neurochem 1989;53:1333-1340.

51. Zlokovic BV, Begley DJ, Chain-Eliash DG. Blood-brain barrier permeability to leucine-enkephalin, D-alanine2-D-leucine5-enkephalin and their N-terminal amino acid (tyrosine). Brain Res 1985;336:125-132.

52. Segal MB, Preston JE, Collis CS, Zlokovic BV. Kinetics and Na independence of amino acid uptake by blood side of perfused sheep choroid plexus. Am J Physiol 1990;258:F1288-F1294.

53. Shibata M, Yamada S, Kumar SR, et al. Clearance of Alzheimer's amyloid- $\beta$ (1-40) peptide from brain by LDL receptor-related protein-1 at the blood-brain barrier. J Clin Invest 2000;106:14891499.

54. Cirrito JR, Deane R, Fagan AM, et al. P-glycoprotein deficiency at the blood-brain barrier increases amyloid- $\beta$ deposition in an Alzheimer disease mouse model. J Clin Invest 2005;115:3285-3290.

55. Bell RD, Sagare AP, Friedman AE, et al. Transport pathways for clearance of human Alzheimer's amyloid $\beta$-peptide and apolipoproteins $\mathrm{E}$ and $\mathrm{J}$ in the mouse central nervous system. J Cereb Blood Flow Metab 2007;27:909-918.

56. Monro OR, Mackic JB, Yamada S, et al. Substitution at codon 22 reduces clearance of Alzheimer's amyloid- $\beta$ peptide from the cerebrospinal fluid and prevents its transport from the central nervous system into blood. Neurobiol Aging 2002;23:405-412.

57. Van Uden E, Mallory M, Veinbergs I, Alford M, Rockenstein E, Masliah E. Increased extracellular amyloid deposition and neurodegeneration in human amyloid precursor protein transgenic mice deficient in receptor-associated protein. J Neurosci 2002;22:92989304.

58. Tamaki C, Ohtsuki S, Iwatsubo T, et al. Major involvement of low-density lipoprotein receptor-related protein 1 in the clearance of plasma free amyloid $\beta$-peptide by the liver. Pharm Res 2006; 23:1407-1416.

59. von Arnim CA, Kinoshita A, Peltan ID, et al. The low density lipoprotein receptor-related protein (LRP) is a novel $\beta$-secretase (BACE1) substrate. J Biol Chem 2005;280:17777-17785.

60. Sagare A, Deane R, Bell RD, et al. Clearance of amyloid- $\beta$ by circulating lipoprotein receptors. Nat Med 2007;13:1029-1031.

61. Farkas E, Luiten PG. Cerebral microvascular pathology in aging and Alzheimer's disease. Prog Neurobiol 2001;64:575-611.

62. Bailey TL, Rivara CB, Rocher AB, Hof PR. The nature and effects of cortical microvascular pathology in aging and Alzheimer's disease. Neurol Res 2004;26:573-578.

63. Wu Z, Guo H, Chow N, et al. Role of the MEOX2 homeobox gene in neurovascular dysfunction in Alzheimer disease. Nat Med 2005; 11:959-965.

64. Paris D, Townsend K, Quadros A, et al. Inhibition of angiogenesis by A $\beta$ peptides. Angiogenesis 2004;7:75-85.

65. Paris D, Patel N, DelleDonne A, Quadros A, Smeed R, Mullan M. Impaired angiogenesis in a transgenic mouse model of cerebral amyloidosis. Neurosci Lett 2004;366:80-85.

66. Deane R, Wu Z, Zlokovic BV. RAGE (yin) versus LRP (yang) balance regulates Alzheimer amyloid $\beta$-peptide clearance through transport across the blood-brain barrier. Stroke 2004:35:2628-2631.

67. Chow N, Bell RD, Deane R, et al. Serum response factor and myocardin mediate arterial hypercontractility and cerebral blood flow dysregulation in Alzheimer's phenotype. Proc Natl Acad Sci U S A 2007; 104:823-828. 